\title{
ОСОБЕННОСТИ ПРАВОСОЗНАНИЯ СТУДЕНТОВ С РАЗНЫМ ИНДЕКСОМ ЖИЗНЕННОГО СТИЛЯ
}

\author{
Пономарев Вадим Петрович
}

В данной статье представлены данные исследования особенностей правосознания у бакалавров разной профессиональной направленности на основе анализа их отношения к правовой регламентации жизни как определенной личностной ченности. В качестве теоретической основы работы рассматривается современная общепсихологическая теория смысла и смыслообразования. Это позволяет выявить новые аспекты правосознания для исследования и дополнить его традиционные трактовки. Правосознание, которое зачастую в научной литературе определяют как форму общественного сознания, в реальности обобщает представление конкретного человека о том, что является законным, а что нет, и по сути является его индивидуальным, личностным смыслом, раскрывающимся при осознании правовых основ существования в реальном жизненном мире. C nомощью специально разработанной анкеты было проведено эмпирическое исследование, которое позволило выявить уровни развития правосознания у респондентов: низкий (респондент плохо информирован по вопросам правовой регламентации своей жизни и не понимает, для чего ему необходимы знания, связанные с правом и законодательством), средний (респондент понимает межличностные формы смысла, заключенные в предложенных для оченки правовых нормах и положениях, может интерпретировать их значение для своей собственной жизни), высокий (понимает значение правовых норм и законодательства как для жизни всего общества, так и для себя лично, может наделить их личностно-смысловыми интерпретациями, соотнести их с различными жизненными контекстами, выделить их общие и специфические характеристики, а самое главное, определить их иенность для своего индивидуального жизненного мира). Далее была проведена психометрическая диагностика с использованием методики «Индекс жизненного стиля». Было выявлено, что уровень правосознания связан с определенными зашитными механизмами личности. Для психологов с высоким уровнем развития правосознания наиболее выраженным выступает механизм замещения, а для юристов - рационализация.

Ключевые слова: личность, ченности, смысловая сфера, правосознание, смысл, смыслообразование, механизмы защиты, поведенческие стратегии, замещение, отрицание, рационализация. 


\section{Введение}

Правосознание на протяжении многих десятилетий привлекает внимание ученых-гуманитариев. В современной научной литературе представлено достаточно большое количество исследований, посвященных изучению проблем, связанных с формированием правосознания у молодого поколения. Это и достаточно солидные теоретические работы А. С. Гречина (2001), Ю. К. Погребной (2011), Е. В. Уваркина (2004), анализирующие проблему правосознания в контексте философских, социологических и правовых наук, и практико-ориентированные работы, ставящие своей целью создать методический арсенал средств для эмпирического изучения данного феномена как конструкта психологической природы [6].

Правосознание рассматривается как совокупность взглядов, ценностных ориентаций, выражающих личностные установки, актуализирующие отношения людей к конкретным законам и к правосудию в целом. По сути, это вера человека в то, что законодательная система, позиционируемая государством как система определенных прав и обязанностей человека по отношению к обществу, государству, окружающим людям, является его личностной ценностью и основанием для определенных стратегий поведения. Правосознание, которое зачастую в научной литературе определяют как форму общественного сознания, в реальности обобщает представление конкретного человека о том, что является законным, а что нет, и по сути является его индивидуальным, личностным смыслом, раскрывающимся при осознании правовых основ существования в реальном жизненном мире. В традиционных учебниках по общей и юридической психологии, чаще всего при определении психологической составляющей правосознания, говорится, что психологическую основу этой области сознания составляют привычки, чувства, эмоции людей в отношении правовых явлений. Однако такая трактовка не соответствует современным психологическим интерпретациям, в частности теории смысла и смыслообразования. С точки зрения именно этого современного научного подхода, правосознание не просто включает знание действующего права, его принципов и требований, окрашенных определенным оценочным отношением (по принципу хорошо/плохо), но и обязательно отражает уровень личностной «пристрастности» к правовой регламентации своей собственной жизни, отражает уровень насыщенности личностным смыслом тех аспектов поведения, которые регулируются существующими правовыми нормами. Конституция, законодательство страны, правовые акты и нормативы есть не просто совокупность значений, которые человек постигает на протяжении всего жизненного пути, они потенциально являются внеличностными формами существования смысла как интенции 
к тому, что индивид может в процессе постижения их содержания раскрыть «смысл для себя», переводя его из потенциальной в актуализированную зону познаваемого.

Методы исследования: анализ современных трактовок правосознания в контексте различных научных подходов, интерпретация правосознания как компонента смысловой сферы личности, анкетирование, контентанализ, методика «Индекс жизненного стиля» (Р. Плутчика, Г. Келлермана, Г. Конте (1979) в адаптации Л. И. Вассермана, О. Ф. Ерышева, Е. Б. Клубовой (2007)).

\section{Основное содержание исследования}

Рассматривая механизмы формирования и актуализации правосознания на личностном уровне, важно акцентировать внимание на двух значимых аспектах данной проблемы.

Во-первых, необходимо понимать, как именно функционирует механизм смыслообразования при формировании правовых ценностей как смысловых образований. Исходным условием возникновения смысла, согласно современной общетеоретической интерпретации, источником смыслообразования является жизненный мир человека, заметно отличающийся от «общего» мира, не включенного в орбиту жизнедеятельности индивидуума. В соприкосновении «внешнего мира», в качестве компонента которого как раз и необходимо рассматривать воздействие нормативно-правовой регламентации жизни, и жизненного мира индивида происходит личностная актуализация, порождающая, в свою очередь, ситуативные смыслы, питающие и обогащающие систему «становящихся» ценностей - это актуальная зона смыслообразования. Наряду с ней, имеются и потенциальные зоны: потенциальная зона жизненного мира (ресурсы объективной действительности, не попавшей в орбиту жизненного мира) и потенциальная зона становления и развития устойчивых смысловых образований (активно не задействованные ресурсы сознания).

Взаимодействие смыслов личности и жизненного мира, возникновение личностных смыслов в одном смысловом континууме, порождают все более сложные смысловые уровни в развитии - от относительно простых личностных смыслов и смысловых установок до устойчивых смысловых образований (смысловые диспозиции, конструкты, ценности) [9], которые остаются с человеком на всю дальнейшую жизнь. Если внешнее воздействие, в качестве которого можно рассматривать познание человеком правовых основ жизни, вызывает смысловую актуализацию, то можно предположить, что они оказывают существенное влияние на становление и развитие человека, в ситуациях постижения принципов и требований права [1,9]. 
В качестве ведущего смыслообразующего механизма при этом выступает диалог, понимаемый в психологии смыслообразования широко, побахтински, как диалог культур, как технология воздействия на ценностносмысловые образования личности - как диалог личностных ценностей и ценностей внешнего мира, осуществляемый вместе с тем в узкой точке индивидуального сознания человека как субъекта, активно осваивающего правовые основы жизни. Внутренняя борьба влечений и осознанной целесообразности, выбор эмоционального и рационального, желаний и рассудочной деятельности - за всем этим «пульсирует» диалог таких смысловых образований, которые присущи различным этажам психики индивидуума и которые могут актуализировать его ценностные приоритеты, в частности в ситуациях, когда человек сталкивается с нормативноправовой регламентацией жизни [2].

Можно выделить составные части целостного процесса выведения правовых норм на ценностно-смысловой уровень и описать соответствующую динамику смыслообразования: смысловая дивергенция (смысловой выбор) - раскрытие смысла (понимание) - реализация смысла (инициация реального действия) - смысловой след (переживание, установка для восприятия последующей информации) [2].

Во-вторых, надо понимать, что выведение правовых норм на смысловой уровень имеет свою специфику. В отличие от целого ряда других ценностных отношений, правосознание как компонент личностного развития не может возникнуть мгновенно. Механизм замыкания жизненных отношений, подробно описанный Д. А. Леонтьевым (1999), здесь не работает. Сутью замыкания является встреча субъекта с объектом или явлением, результатом которой становится неожиданное спонтанное обретение этим объектом весомого жизненного смысла, т. е. важного места в жизни субъекта, но правосознание не возникает одномоментно. Не сработает здесь и механизм индукции, когда человек пытается заставить себя оценочно относиться к тому, что не порождает смысла (по выражению Д. А. Леонтьева, механизм «стерпится-слюбится»). То, что можно реально рассматривать как инициации развития правосознания, лежит в плоскости пролонгированного воздействия на ценностную сферу субъекта восприятия. Это, прежде всего, идентификация с определенной социальной группой или общностью в процессе социогенеза, что приводит к присвоению смысловых ориентаций, характеризующих правовую культуру и законодательные требования данной социальной общности. При запуске механизма идентификации формируются т. н. высшие смыслы (патриотизм, гражданские ценности, ценности культуры, правосознание) - как априорно существующая смысловая инстанция, включающая мировоззрение, смысл 
жизни, самоотношение. Здесь, на этом уровне смыслового развития, новый смысл не возникает, а уже существующий смысл переходит в новую форму существования или на новый носитель. «Смысловые структуры этого уровня не наполняются смыслом из какой-либо еще более высокой смыслообразующей инстанции - такой инстанции нет» [9, с. 354]. Именно эти ведущие смысловые ориентиры «становятся в дальнейшем смыслообразующими основаниями жизнедеятельности» [9, с. 356], именно на этом смысловом поле индивидуального сознания познающего происходят индивидуально-неповторимые акты смыслопорождения. Через систему личностных ценностей человек, используя все механизмы порождения смыслов, приходит к «полаганию смыслов» - когда смысл постигаемого содержания раскрывается через «особый экзистенциальный акт, в котором субъект своим сознательным и ответственным решением устанавливает значимость чего-либо в своей жизни» [9, с. 354]. Если такой механизм запущен, то можно говорить о «смысловом консонансе» как поле, в котором ценности, позиционируемые обществом и государством как позитивные, становятся ценностями познающего и осмысливающего их субъекта.

Однако, в качестве инициирующего фактора для личностного «присвоения» ценностей права могут послужить не только ситуации, когда нормативно-правовое регулирование вызывает позитивное принятие, но и ситуации, когда установки познающего приходят в противоречие с тем, что предлагает правовая система или законодательство (ситуации «смыслового диссонанса»). Возникает эффект «столкновения» смыслов, которое происходит при встрече субъекта - носителя внутреннего смыслового мира - с другими смысловыми мирами. «Перед субъектом встает проблема сопоставления разных вариантов осмысления действительности, которые могут различаться по степени полноты, разработанности, а также содержательно, и характеризоваться разной степенью противоречивости. Столкновение с иным смысловым миром приводит к осознанию относительности своего, и результатом взаимодействия двух смысловых миров может являться либо обогащение смыслового мира субъекта, либо его более или менее радикальные перестройки, связанные не только с обретением новых смыслов, но и с разрушением старых» $[9$, с. 36].

Анализ правосознания в контексте современной теории смысла и смыслообразования позволяет выявить связь между уровнем развития правосознания и уровнем развития смысловых образований личности. Эта проблема и определила цель данного исследования. Для выявления уровней развития правосознания студентов разной профессиональной направленности (в исследовании принимали участие 238 бакалавра старших 
курсов (3-4) разных факультетов ЮФУ: физики, биологи, филологи, психологи, юристы) была разработана специальная анкета, ориентированная на выявление уровней правовой информированности и ценностно-смысловых установок при оценке правовых норм поведения. Данная анкета позволила выявить три уровня развития правосознания у студентов: низкий (респондент плохо информирован по вопросам правовой регламентации своей жизни и не понимает, для чего ему необходимы знания, связанные с правом и законодательством), средний (респондент понимает межличностные формы смысла, заключенные в предложенных для оценки правовых нормах и положениях, может интерпретировать их значение для своей собственной жизни), высокий (понимает значение правовых норм и законодательства как для жизни всего общества, так и для себя лично, может наделить их личностно-смысловыми интерпретациями, соотнести их с различными жизненными контекстами, выделить их общие и специфические характеристики, а самое главное, определить их ценность для своего индивидуального жизненного мира). Ответы бакалавров были проанализированы методом контент-анализа. Полученные результаты представлены в Таблице 1:

Таблица 1

Уровни развития правосознания у студентов разной профессиональной направленности

\begin{tabular}{|c|c|c|c|c|}
\hline № & Специальность & Низкий уровень & Средний уровень & Высокий уровень \\
\hline 1 & физики & $12 \%$ & $88 \%$ & - \\
\hline 2 & биологи & $15 \%$ & $74 \%$ & $11 \%$ \\
\hline 3 & филологи & - & $63 \%$ & $37 \%$ \\
\hline 4 & психологи & $7 \%$ & $61 \%$ & $32 \%$ \\
\hline 5 & юристы & - & $74 \%$ & $26 \%$ \\
\hline
\end{tabular}

Бакалавры естественнонаучных специальностей относятся к праву и законодательству более отчужденно, чем гуманитарии, которые при интерпретации вопросов, связанных с этими областями жизни, в большей степени наделяют их определенным ценностным отношением. Почти треть филологов и психологов считают, что правосознание является важнейшей составляющей не только для регламентации взаимодействия человека с окружающими, но и для рефлексии самого себя как носителя духовнонравственных черт. В их представлении право неразрывно связано с моралью и зачастую является социальным ориентиром для человека при оценке и понимании сущности тех или иных событий. Будущие профессиональные юристы в меньшей степени склонны к трактовке права как нравственного 
регулятора поведения человека. При этом, они, в отличие от бакалавров других специальностей, рассматривают законодательство не как совокупность неизменно-устойчивых положений, определяющих нравственные устои общественных взаимоотношений, а как нечто динамически развивающееся, - то, что не просто отражает изменения, происходящие в жизни общества и государства, но и может существенно влиять на специфику формирования общественных приоритетов. Определяя свое отношение к праву как определенной ценности, они, главным образом, выделяют его значимость не столько для себя лично, сколько рефлексируют его ценность как межличностную форму существования смысла в контексте культуры и общественных норм жизни общества.

На следующем этапе исследования был проведен сравнительный анализ по уже сформированным группам. С использованием специализированной диагностики (методика Р. Плутчика, Г. Келлермана, Г. Конте (1979) в адаптации Л. И. Вассермана, О. Ф. Ерышева, Е. Б. Клубовой (2007)) были выявлены различия у студентов с разным уровнем развития правосознания по индексу жизненного стиля как целостной личностной характеристики, которая отражает специфику оценочной и поведенческой динамики через систему психологических защит. Опросник включает 97 утверждений, требующих ответа по типу «верно/неверно». Измеряются восемь видов защитных механизмов: вытеснение, отрицание, замещение, компенсация, реактивное образование, проекция, интеллектуализация (рационализация) и регрессия. Каждому из этих защитных механизмов соответствуют от 10 до 14 утверждений, описывающих личностные реакции человека, возникающие в различных ситуациях. Данная методика основана на концептуальном положении, согласно которому механизмы защиты можно рассматривать как важную характеристику смысловой сферы личности. На основе ответов строится профиль защитной структуры «Я» обследуемого, которая позволяет определенным образом описать поведение человека в ситуациях, требующих оценочных действий. Данная методика позволяет выявить готовность человека поступать по типу определенной поведенческой стратегии: игнорирование, отчуждение, присвоение.

Подсчет «сырых» баллов позволил выявить определенные шкалы «эгозащит», которые доминировали в разных профессиональных группах и группах с разным уровнем развития правосознания (рис. 1).

\section{Заключение}

Только в двух профессиональных группах психологов и юристов были выделены наиболее характерные для них механизмы защит. Для психологов - это замещение, которое зачастую в психологии характеризуется как 


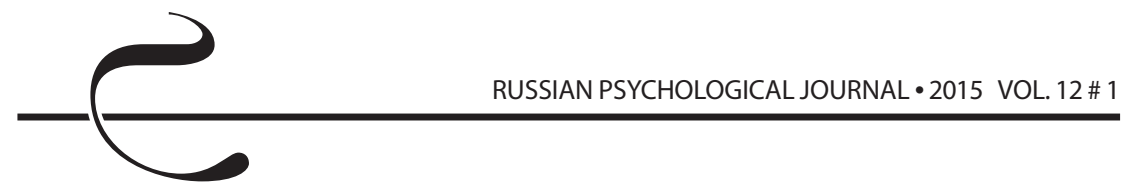

механизм переноса, при котором недосягаемая цель (например, изменение законодательства, неудовлетворительная система правоприменения в обществе, коррупция и т. д.) замещается более приемлемыми. Этот механизм инициирует активные поведенческие реакции. Корреляционный анализ показал, что существует определенная связь между $(p<0,01)$ уровнем правосознания и стремлением к использованию переноса как механизма защиты. Этот механизм наиболее характерен для студентов с высоким уровнем развития правосознания, которые рассматривают правовые и законодательные нормы жизни как личностную ценность. Эти студенты рефлексируют, что часть проблем, связанных с воплощением этих идей в реальной жизни, им неподвластны, но они готовы к активным формам продвижения своих правосознательных ценностей (отстаивание прав человека, продвижение общегражданских ценностей, оказание психологической помощи и т. д.). Их поведенческую стратегию в отношении права как компонента общественного сознания можно характеризовать как стратегию присвоения.

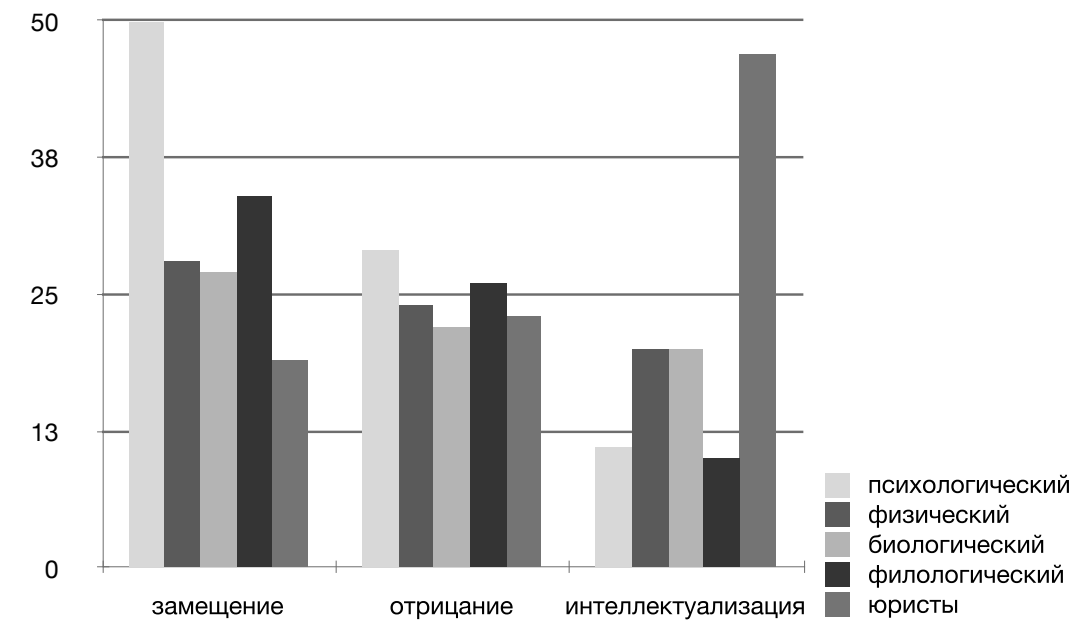

Рисунок 1. Распределение «эго-защит»

по группам профессиональной направленности

Студенты естественнонаучных специальностей и филологи ориентированы на механизм отрицания, при котором основные поведенческие стратегии игнорирование и отчуждение. В особенностях их правосознания это проявляется тенденцией рассматривать правовые аспекты жизни как то, что не является существенной частью их жизненного мира. 
Бакалавры-юристы с высоким уровнем развития правосознания в основном показали превалирование интеллектуализации (рационализация), при котором важным компонентом поведения становится поиск причин и мотивов своих поступков во внешней среде. Это отражается в особенностях их правосознания. Они верят в то, что проблемы общества и государства возможно решить через совершенствование законодательства, и готовы сами активно работать в этом направлении.

\section{Литература}

1. Абакумова И. В., Кагермазова Л. Ц., Савин В. А. Диалог культур как смыслотехнология формирования установок толерантного сознания и поведения студентов вуза // Российский психологический журнал. 2013. - Т. 10. - № 1. - С. 46-59.

2. Абакумова И. В. Смысл как научная категория и влияние его концептуальных интерпретаций на теорию образования и обучения // Научная мысль Кавказа. - 2002. - № 13. - С. 142-146.

3. Байниязов Р. С. Правосознание: Психологические аспекты // Правоведение. - 1998. - № 3. - С. 16-21.

4. Васильев В. Л. Юридическая психология: учебник для вузов. 6-е изд. СПб.: Питер, 2009. - 608 с.

5. Вассерман Л. И., Ерышев О. Ф., Клубова Е. Б. Психологическая диагностика индекса жизненного стиля (Пособие для психологов и врачей). - СПб.: Изд-во СПбНИПНИ им. В. М. Бехтерева, 2005. - 50 с.

6. Веденкин Н. А. О необходимости диагностики уровня развития правосознания личности кандидата на службу в органы внутренних дел // Вопросы психологии экстремальных ситуаций. - 2011. - № 2.

7. Гулевич О.А. Структура правосознания и поведение в правовой сфере // Психологические исследования: электрон. науч. журн. - 2009. - № 5 (7).

8. Ильин О. Ю. Правосознание: постнеклассическое правопонимание и личностная проекция: дисс. ... канд. филос. наук. - Тверь: Тверской государственный технический университет, 2011. - 198 с.

9. Леонтьев Д. А. Психология смысла. Природа, строение, динамика смысловой реальности. - М.: СМЫСЛ, 2003. - 487 с.

10. Ростова Е. Н. Самосознание личности и представление о смысле своей жизни у взрослых // Северо-Кавказский психологический вестник. 2012. - Т. 10. - № 3. - С. 45-48.

11. Смирнов В. Н. Юридическая психология. - М.: ЮНИТИ-ДАНА, 2010. $319 \mathrm{c}$.

12. Ясюкова Л. А. Правосознание: диагностика и закономерности развития // Прикладная психология. - 2000. - № 4. - С. 1-13. 
13. Abakumova I. V., Kruteleva L. Ju. Tolerance in the Structure of Life-Sense Strategies of the Modern Youth // The 13th European Congress of Psychology. -2013.

14. Halpern D. Moral Values, Social Trust and Inequality // British Journal of Criminology. - 2001. - Vol. 41. - pp. 236-251.

15. Kruteleva L. Ju., Abakumova I. V. Life-sense Strategies as a MotivationalDynamic Characteristic of a Person // Procedia - Social and Behavioral Sciences. - 2013. - 86. - pp. 35-41.

16. Leung K. Social Axioms. The Search for Universal Dimensions of General Beliefs about how the World Functions // J. of Cross-Cultural psychology. 2002. - Vol. 33. - pp. 286-302. 